\title{
IDENTIDADE ÉTNICA, AUTOGOVERNANÇA E ATIVOS BIOLÓGICOS: UM OLHAR A PARTIR DA EXPERIÊNCIA EM UMA COMUNIDADE QUILOMBOLA
}

\author{
ETHNIC IDENTITY, SELF-GOVERNANCE AND BIOLOGICAL \\ ASSETS: A LOOK FROM A QUILOMBOLA \\ COMMUNITY EXPERIENCE
}

\author{
L'IDENTITÉ ETHNIQUE, L'AUTOGOUVERNANCE ET LES \\ ACTIFS BIOLOGIQUES: UN REGARD SUR L'EXPÉRIENCE \\ D'UNE COMMUNAUTÉ QUILOMBOLA
}

Josué de Lima Carvalho[i] Ynis Cristine de Santana Martins Lino[ii] Ticiane Lima dos Santos[iii]

\section{RESUMO}

Dentre as diversidades de povos tradicionais, este trabalho tem por objeto de estudo investigar uma experiência de autogestão de ativos biológicos em "Comunidades Remanescentes Quilombolas" constituídas pelos descendentes dos escravos negros que, no processo de resistência à escravidão, originaram grupos sociais que ocupam um território comum e compartilham características culturais, sociais e econômicas até os dias de hoje. Seguindo os conceitos já expressos a piscicultura, como prática, é uma forma de busca para alternativas à reprodução social. Portanto, o objetivo deste estudo se encontra na busca entre a relação da gestão do território em uma comunidade quilombola e a sua produção agropecuária coletiva utilizando conceitos relacionados a autogestão e reconhecimento

\section{ABSTRACT}

Among the diversities of traditional peoples, this study aims to investigate a selfmanagement of biological assets in Quilombola remaining communities constituted by the descendants of black slaves who fought against slavery and created social groups that occupy a common territory and share cultural, social and economic characteristics to this day. Following the concepts previously stated, fish farming as a practice is a way of searching for alternatives for social reproduction. Therefore, the objective of this study is to identify the relation between territory management in a quilombola community and its collective agricultural production based on concepts related to self-management and recognition of biological assets. The method object of this study is the Casing

\section{RÉSUMÉ}

Parmi les diversités des peuples traditionnels, ce travail a pour objectif étudier l'expérience d'autogestion des actifs biologiques dans les «communautés restantes de Quilombola» constituées par les descendants d'esclaves noirs qui, dans le processus de résistance à l'esclavage, sont à l'origine de groupes sociaux qui occupent un territoire commun et partagent des caractéristiques culturelles, sociales et économiques jusqu'à nos jours. Suivant les concepts déjà exprimés, la pisciculture en tant que pratique est un moyen de rechercher des alternatives pour la reproduction sociale. Par conséquent, l'objectif de cet étude se trouve dans la recherche de la relation entre la gestion du territoire dans une communauté de quilombola et sa production agricole collective en utilisant des concepts liés à l'autogestion et à la 
de ativos biológicos. Utilizou-se o Casing (RAGIN; BECKER, 1992) enquanto método e o objeto desse estudo se concentrou na comunidade Quilombola Forte do Castelo em Tomé-Açu, no estado do Pará. Evidenciou-se que a comunidade pratica a autogestão a partir da autogovernança, a qual possibilita a construção de instituições legítimas. Os resultados obtidos expressam a influência que a comunidade tem da autogovernança e a sua relação com a piscicultura com meio de produção.

\section{Palavras-chave:}

Autogovernança; Ativo Biológico; Comunidades Tradicionais.
(RAGIN; BECKER, 1992) method and it is centered on the Forte do Castelo quilombola community in Tomé-Açu, in Pará. The community practices selfmanagement based on Selfgovernance, which allows the construction of legitimate institutions. The results show the community's influence on self-governance and its relationship with fish farming as a means of production.

\section{Keywords:}

Self-governance; Biological

Asset; Traditional

Communities.

\section{INTRODUÇÃO}

O início do processo de luta pela posse da terra entre os quilombolas remete aos séculos XVI e XVII, quando países que ainda eram colônias europeias assinaram tratados para a demarcação de áreas de liberdade para os remanescentes de quilombos, que passaram a possuir 0 controle coletivo do território (para agricultura, coleta, caça e pesca), significando, com isso, o controle sobre um espaço no qual se poderia desenvolver uma cultura autônoma (PRICE, 1996).

No Brasil, a partir da promulgação da Constituição Federal de 1988, passou a garantir reconhecimentos de territórios dos remanescentes das comunidades dos quilombos que estivessem

ocupando suas terras. Cada uma dessas comunidades apresenta formas de uso específicas dos recursos naturais, estando esse fato relacionado à distribuição espacial do ambiente em seus territórios (BARBOSA; MARIN, 2010), a partir de construções sociais como a autogovernança, enquanto estrutura de compartilhamento de poder particular que permite governar e ser governado, simultaneamente, instrumentalizado pela autogestão.

Nesse interim, a autogestão se dá quando os comunitários são gestores, ou seja, coproprietários em regime de propriedade comum, com poder de deliberar e participar das decisões tomadas em conjunto nas assembleias da Associação de Moradores e, ao reconnaissance des actifs biologiques. On a utilisé Casing (RAGIN; BECKER, 1992) comme objet et méthode de cet étude qui est concentré sur la communauté de Quilombola Forte do Castelo à Tomé-Açu, dans l'État du Pará. II a démontré que la communauté pratique l'autogestion basée sur l'autogouvernance, ce qui permet la construction d'institutions légitimes. les résultats obtenus expriment l'influence de la communauté sur I'autonomie gouvernementale et sa relation avec la pisciculture avec un moyen de production.

\section{Les mots-clés:}

L'Autogouvernance; Les Actifs biologiques; Les Communautés traditionnelles.

mesmo tempo, geridos por essas decisões. Destaca-se que as interações entre os atores sociais que se relacionam com o território quilombola produz desafios estruturais e sociais concernentes às interações baseadas em sistemas de uso comum, em território coletivo, fato este que gera conflitos.

Nesse contexto, as comunidades quilombolas exercem atividades econômicas com base comum de recursos (Termo em inglês criado por Ostrom (1990)) em seus territórios, sendo essas atividades consideradas como processos de produção, nos quais estão inseridos ativos biológicos. Isso porque: I) a comunidade quilombola possui o título de propriedade da terra, sendo cada quilombola um coproprietário com direitos de propriedade, II) o processo de 
produção pressupõe um benefício pelo consumo ou venda/troca, III) é possível atribuir um valor monetário e IV) esses ativos são resultados de eventos passados. Essas atividades econômicas geram receitas e/ou meios de subsistência que são capturados e distribuídos entre atores.

No contexto brasileiro, a contabilidade rural, no que se refere principalmente a avaliação dos ativos biológicos, sofreu grandes mudanças a partir da convergência das normas brasileiras de contabilidade aos padrões internacionais. Esse processo foi possível a partir da institucionalização do Comitê de Pronunciamentos Contábeis (CPC) pelo órgão regulamentador da Contabilidade, O Conselho Federal de Contabilidade (CFC). A International Accounting Standard (IAS), especificamente a IAS 41 - Agricultura regulamenta a contabilização, mensuração, apresentação e divulgação relacionadas a atividade agrícola (IFRS, 1999), de modo que a Norma Brasileira de Contabilidade Técnica Geral (NBC TG) 29 (CFC, 2015), está alinhada à IAS 41 e regula os métodos de avaliação, mensuração e reconhecimento dos ativos biológicos.

Na literatura acadêmica, a agricultura é tratada de várias formas, sendo que em uma breve definição pode ser considerada como a artificialização pelo homem do meio natural, representado como todas as atividades de exploração das terras (BARROS, 1975). As práticas agrícolas são comuns a vários grupos em diversas regiões do Brasil e com o intuito de fortalecê-las a ocontabilidade se demonstra como uma ferramenta essencial de controle e gerenciamento

independentemente do tipo de produção ou das características de quem a pratica.

No Brasil é notável a representatividade das empresas rurais, principalmente no que se refere ao setor da agropecuária. Para que essas organizações possam crescer e se desenvolver ainda mais, é necessária uma prática contábil satisfatória que corresponda às necessidades dessas entidades, sejam elas empresas rurais, cooperativas, ou até mesmo para o pequeno produtor que comercializa sua produção para fins de subsistência.

Assim, dentre os praticantes de atividades rurais, as comunidades e povos tradicionais também se utilizam desse meio para a sua subsistência. Esses grupos étnicos podem ser definidos, de acordo com Decreto no 6.040, de 7 de fevereiro de 2007 que institui a Política Nacional de Desenvolvimento Sustentável dos Povos e Comunidades Tradicionais. Como grupos que são diferenciados culturalmente, e se reconhecem como tais. Esses grupos possuem suas próprias formas de organização social, ocupando e usufruindo de territórios que são condicionados para a sua reprodução cultural, social, religiosa, ancestral e econômica, utilizando os seus conhecimentos, inovações e práticas gerados para a transmissão pela tradição (BRASIL, 2007).
Dentre as diversidades de povos tradicionais, este trabalho tem por objeto de estudo investigar uma experiência de autogestão de ativos biológicos em comunidades remanescentes quilombolas constituídas por descendentes de escravos negros que, no processo de resistência à escravidão, originaram grupos sociais que ocupam um território comum e compartilham características culturais, sociais e econômicas até os dias de hoje. (FUNDAÇÃO PALMARES, 2007)

Os povos tradicionais quilombolas, possuem grande influência de práticas agropecuárias e elas podem ser consideradas como uma atividade exemplar no desenvolvimento sustentável, pois considera os recursos naturais e ambientais como recursos produtivos, cuja conservação está fortemente vinculada ao bem-estar social e econômico da população regional. (MELO; MELO; SILVA, 2015). Contudo, na academia há parcial discordância desse fato, pois a prática agropecuária vegetal também se demonstra como uma base de desenvolvimento de vulto muito frágil que se justifica, principalmente, na pobreza dos seus habitantes e a sua relação com a mão de obra marginal (HOMMA, 1990).

As práticas agropecuárias desenvolvidas nas comunidades tradicionais estão vinculadas a utilização dos seus recursos naturais comuns, sejam eles: água, território, espécies de árvores nativas, entre outras. $\mathrm{E}$ para que esses recursos sejam mantidos por longos períodos, se pratica a autogestão. 
Conforme os parágrafos acima, as comunidades tradicionais possuem um forte vínculo com atividades extrativistas e de plantio, e utilizam as suas respectivas produções para sua subsistência através de consumo e comercialização. Desse modo, este estudo tem por objetivo analisar a relação entre a gestão do território em uma comunidade quilombola e a sua produção agropecuária coletiva utilizando conceitos relacionados a autogestão. A produção agrícola foi analisada do ponto de vista contábil, utilizando como base a Norma Brasileira de Contabilidade Técnica Geral (NBC TG) 29 (R2) (CFC, 2015), que dispõe sobre o tratamento e o reconhecimento de ativos biológicos e produtos agrícolas.

Para tanto tem-se o seguinte problema de pesquisa: como se dá o processo de autogestão do território e dos ativos biológicos em uma comunidade quilombola na estrutura de autogovernança? Portanto, este trabalho tem possui como unidade empírica de análise a comunidade quilombola

Forte do Castelo na região do Marupaúba, localizada no município de Tomé-Açu (PA).

\section{COMUNIDADES TRADICIONAIS}

O processo de colonização portuguesa a partir do século XVI plasmou características marcantes na população rural, criando um modelo de adaptação ao meio. Apesar das diferenças regionais, percebese, de acordo com Arruda (1999), que essas comunidades tradicionais

possuem características em comum que ainda hoje marcam esses grupos isolados em distintas regiões do Brasil. $O$ autor ressalta ainda que esse fato se deve à grande influência de populações indígenas e ao caráter cíclico e irregular do avanço da sociedade nacional sobre o interior do país.

As comunidades tradicionais concebem a natureza como fonte que garante a vida e a reprodução social e, sendo assim, não partem de uma concepção preservacionista sobre a natureza (ALLEGRETTI, 2008; DIEGUES, 2011) pois não "planejam para a terra uma produção a ponto de aplicarem todas as suas forças e de seus familiares na geração de excedentes de forma excessiva" (CARDOSO, 2015, p 82).

Através do Decreto no 6.040/2007 (BRASIL, 2007) se aferiu definições relevantes às comunidades tradicionais e como se dá o seu relacionamento com 0 ambiente ao seu redor. No Artigo 3, inciso II, se define os territórios tradicionais como espaços necessários para que os grupos se reproduzam culturalmente, socialmente e economicamente, seja de forma temporária ou permanente. Ainda no Artigo 3, no inciso III, O Decreto explica a relação dos grupos tradicionais com o desenvolvimento sustentável com intuito de garantir a melhoria da qualidade de vida da geração, progredindo às futuras gerações.

Anexo ao Decreto se encontra a Política Nacional de Desenvolvimento de Povos e Culturas Tradicionais que tem grande importância na garantia de direitos sociais, o que bem se pode identificar junto ao seu objetivo:
Dentre as diversidades de povos tradicionais, este trabalho tem por objeto de estudo investigar uma experiência de autogestão de ativos biológicos em comunidades remanescentes quilombolas constituídas por descendentes de escravos negros que, no processo de resistência à escravidão, originaram grupos sociais que ocupam um território comum e compartilham características culturais, sociais e econômicas até os dias de hoje. (FUNDAÇÃO PALMARES, 2007)

Os povos tradicionais quilombolas, possuem grande influência de práticas agropecuárias e elas podem ser consideradas como uma atividade exemplar no desenvolvimento sustentável, pois considera os recursos naturais e ambientais como recursos produtivos, cuja conservação está fortemente vinculada ao bem-estar social e econômico da população regional. (MELO; MELO; SILVA, 2015). Contudo, na academia há parcial discordância desse fato, pois a prática agropecuária vegetal também se demonstra como uma base de desenvolvimento de vulto muito frágil que se justifica, principalmente, na pobreza dos seus habitantes e a sua relação com a mão de obra marginal (HOMMA, 1990)

As práticas agropecuárias desenvolvidas nas comunidades tradicionais estão vinculadas a utilização dos seus recursos naturais comuns, sejam eles: água, território, espécies de árvores nativas, entre outras. E para que esses recursos sejam mantidos por longos períodos, se pratica a autogestão. 


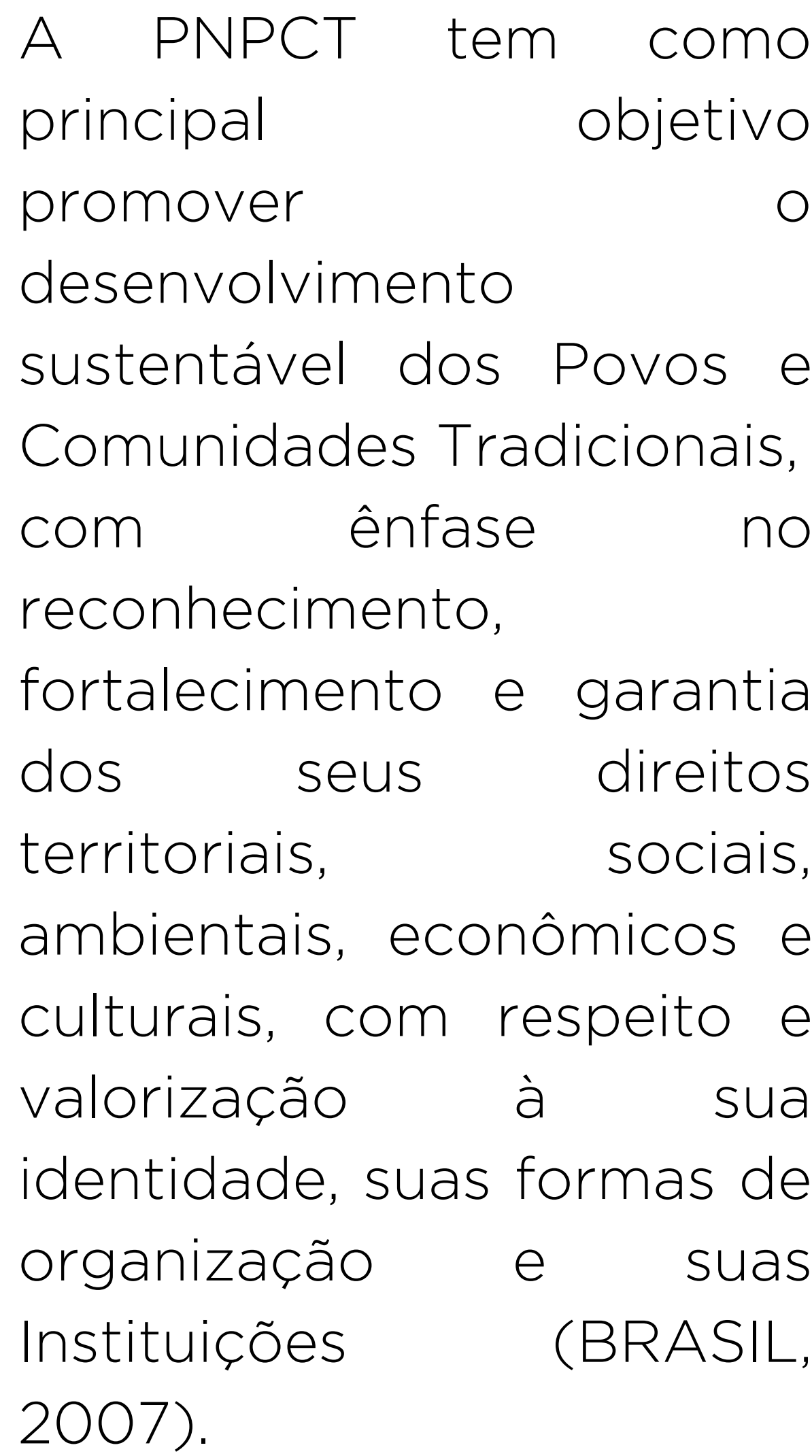

As técnicas de plantio desenvolvidas por esses grupos também sofrem forte influências da população indígena (roça consorciada, itinerante, com base na queimada, tipo slashand-burn: em uma tradução aproximada, representa o processo de abertura de mata e posterior queimada, no intuito de "limpeza" do terreno) e de artefatos como as peneiras, os pilões, o ralo, o tipiti e outros implementos que fazem parte da cultura rústica brasileira (ARRUDA, 1999).

\section{Comunidades Quilombolas}

O termo quilombo possivelmente se refere a um conceito próprio dos africanos bantos que vem sendo modificado através dos séculos. O significado está relacionado aos acampamentos de guerreiros nas florestas, existindo muitas outras concepções dadas sua complexidade. "Na tradição popular no Brasil há muitas variações no significado da palavra quilombo, ora associado a um lugar ("quilombo era um estabelecimento singular"), ora a um povo que vive neste lugar ("as várias etnias que o compõem")" (GlUCCl, 1992).
Ainda na visão de Giucci (1992), diversas instituições no decorrer dos séculos expressaram relação com o termo quilombo, tais como: manifestações populares, relação social, sistema econômico, dentre outros. Há, pelo menos, 12 significados relacionados ou distintos, favorecendo o seu uso para expressar uma grande quantidade de experiências, um verdadeiro aparato simbólico a representar tudo o que diz respeito à história das américas.

O quilombo no Brasil teve a sua origem na época colonia como representação à resistência dos africanos ao escravismo praticado no período, e retorna à cena política no final dos anos de 1970, durante a redemocratização do país. Trata-se, portanto, de uma questão persistente, sendo uma importante dimensão na luta dos afrodescendentes na atualidade (LEITE, 2000).

Como já supracitada, a divisão territorial é uma característica marcante principalmente na zona rural nacional, contudo, os

povos de descendência africana não foram contemplados na primeira lei das terras, em 1850. Somente a partir da Constituição Federal 1988, foram promulgadas as Disposições Transitórias que preveem o reconhecimento da propriedade das terras dos "remanescentes das comunidades dos quilombos".

Diegues et al. (2000) destaca que é necessário pensar a participação democrática na gestão dos espaços territoriais ocupados por populações tradicionais. Desta maneira, para a afirmação do reconhecimento de um quilombo é relevante considerar os modos de vida, as práticas peculiares de manejo dos recursos naturais disponíveis no território. Tais populações tradicionais são assim caracterizadas de acordo com Cunha e Almeida (2001, p.

29):

São grupos que
conquistaram ou estão
lutando para conquistar
(através de meios práticos
e simbólicos) uma
identidade pública que
inclui algumas, não
necessariamente todas, as
seguintes características: o
uso de técnicas ambientais
de baixo impacto, formas
equitativas de organização
social, a presença de
instituições com
legitimidade para fazer
cumprir suas leis; liderança
local e, por fim, traços
culturais que são
seletivamente reafirmados
e reelaborados.

\section{Autogestão e Autogovernança em Comunidades Quilombolas}

Para Ostrom (1990) há uma tendência do poder público em tentar impor instituições uniformes em toda uma jurisdição, sem considerar o contexto local, tornando extremamente difícil essa implantação o que ocasiona que essas instituições sejam percebidas como inefetivas e não equitativas, e os custos para monitoração e fazer cumprir tais instituições, provavelmente, serão maiores do que se estas instituições fossem moldadas pelos atores locais e ajustadas aos contextos locais.

As instituições criadas para governar uma base comum de recursos são menos efetivas quando o governo cria, 
implementa e monitora essas instituições, ao invés das próprias comunidades explorarem os recursos (OSTROM, 1990). Assim, a autogovernança é uma estrutura de compartilhamento de poder que permite a definição e adaptação de regras que permitem os governados se governarem por meio da autogestão. Isso porque, segundo Cançado (2011, p. 105), a autogestão é "um modo de organização do trabalho, onde não há separação entre a concepção e execução, e os meios de produção são coletivos". A autogestão também pode ser entendida enquanto prática, na medida em que é a tomada de decisão coletiva, pois a autogestão é "concebida como a participação dos membros na tomada de decisão" (CANÇADO et al., 2014).

A comunidade quilombola se enquadra na definição de recursos florestais autogovernados (OSTROM et al., 1999), isso porque possui um espaço deliberativo, como a Associação de Moradores, servindo para que os comunitários se envolvam na elaboração e adaptação das regras sobre inclusão ou exclusão de participantes, estratégias de apropriação, obrigações de participantes, monitorização, sancionamento e resolução de conflitos dentro de arenas de escolha coletiva, ou seja, reuniões deliberativas organizadas pelos próprios quilombolas. A autogovernança de recurso florestal pressupõe que os atores, principais usuários, se envolvam em construir socialmente, bem como adaptar regras dentro da escolha coletiva (OSTROM et al., 1999).

\section{Ativos Biológicos}

Marion e ludícibus (p. 15, 2011)

afirmam que ativos são todos os bens e direitos de propriedade da empresa avaliáveis em dinheiro, que representam benefícios presentes ou futuros para a empresa. Em outra definição Marion (p. 57, 2009) sustenta que ativo é o conjunto de bens e de direitos controlado pela empresa. São os itens positivos do patrimônio; trazem benefícios, proporcionam ganho para a empresa. Partindo desse raciocínio, há a necessidade de existência de benefícios futuros a partir desse direito, não sendo ativos os direitos com benefícios nulos ou negativos Hendriksen

Van Breda (1999). O fato é que os ativos representam, em suma, bens e direitos materiais e imateriais, se configurando como índice de riqueza patrimonial.

Otivo biológico com advento das International Financial Reporting Standards (IFRS) é regido pelo Comitê de Pronunciamento Contábeis 29 (CPC, 2009), que estabelece o devido tratamento contábil e as suas respectivas formas de divulgações que variam dependendo da fase em que se encontra esse ativo.

A International Accounting Standards 41 (IAS 41) foi editada pelo International Accounting Standards Committee (IASC, 1989) em dezembro de 2000, após vários anos de discussão, pois a sua primeira versão para consulta pública foi divulgada pelo International Accounting Standards Committee (IASC) em 1994 (RECH; PEREIRA; PEREIRA; CUNHA, 2016). Foi a primeira norma a ser emitida pelo International Accounting Standards Board (IASB), direcionada especificamente para o setor primário, tendo como objetivo normatizar o tratamento contábil das apresentações e divulgações das demonstrações financeiras das entidades relacionadas com atividades agrícolas (WANDELEY; SILVA; LEAL, 2012).

A NBC TG 29 é alinhada IAS 41 e se aplica aos ativos biológicos, exceto plantas portadoras, produção agrícola no ponto de colheita e subvenções governamentais. diferenciação entre os conceitos de ativo biológico, ou seja, animal e/ou uma planta vivos, e produto agrícola, produto colhido de ativo biológico da entidade.

Um ativo biológico pode ser caracterizado como um animal ou planta vivo e sujeitos a um fenômeno denominado transformação biológica. Esse fenômeno consiste no processo de crescimento, degeneração, produção e procriação, causando mudanças de forma qualitativa e quantitativas nesse tipo de ativo. Desse modo, os ativos biológicos possuem entre as suas características mais expressivas a capacidade de mudança, o que implica que durante o período de vida, por exemplo, de um tipo de gado, o mesmo nascerá, crescerá, sofrerá mudanças no seu desenvolvimento e, possivelmente, irá se reproduzir, todos esses fatos são registrados contabilmente havendo gerenciamento e mensuração de todo o processo que esse ativo sofreu.

Conforme a NBC TG 29 （R2 - 
Revisado pela segunda vez) se deve reconhecer um ativo biológico quando, e somente quando: há controle do ativo como resultado de eventos passados; for provável que benefícios econômicos futuros associados com o ativo fluirão para a entidade; $O$ valor justo ou o custo do ativo puder ser mensurado confiavelmente. O valor justo, também denominado "fair value", pode ser considerado como um valor que é pago em uma transação não forçada no mercado, ou seja, o valor que determinado item ou mercadoria está sendo negociado em um mercado competitivo (CFC, 2015).

Para que se possa mensurar a valor justo, se faz necessário obedecer a alguns critérios essenciais para que esse reconhecimento possa ser feito com confiabilidade. A entidade deve utilizar técnicas de avaliação que sejam apropriadas nas circunstâncias e para as quais haja dados suficientes disponíveis para mensurar o valor justo, maximizando o uso de dados observáveis relevantes e minimizando o uso de dados não observáveis, conforme a Norma Brasileira Técnica Geral (NBC TG) 46 (CFC, 2017)

Com o intuito de melhorar a consistência comparabilidade nas mensurações do valor justo e nas suas respectivas demonstrações, a Norma Brasileira Técnica Geral (NBC TG) 46 estabelece uma hierarquia de aplicação do valor justo, que é estabelecida em 3 níveis. A hierarquia de valor justo dá a mais alta prioridade a preços cotados (não ajustados) em mercados ativos para ativos ou passivos idênticos (informações de Nível 1) e a mais baixa prioridade a dados não observáveis (informações de Nível 3) CFC, 2017).

\section{PROCEDIMENTOS METODOLÓGICOS}

Adotou-se o Casing como método de pesquisa, entendido como movimento de construção de caso, constituído de seis invólucros os quais são, segundo Ragin e Becker (1992), níveis de abstração interativos. Considerou-se que "invólucro" é adequado para a tradução, pois remete à ideia de revestimento que cada nível apresenta. No mais alto nível de abstração está a teoria, que fornece a estrutura para pesquisa, mas não estabelece uma base empírica. Entre a teoria e os dados empíricos, no entanto, existem quatro níveis de abstração que são considerados na medida em que se pratica o "revestimento" pelo invólucro para a revisão da literatura.

A unidade empírica de análise foi a comunidade quilombola Forte do Castelo situada no município de Tomé-Açu, estado do Pará, Brasil. Essa comunidade pratica a piscicultura rudimentar para subsistência e/ou venda em pequena escala no mercado local em feiras e, por muitas vezes, em distribuições dos próprios quilombolas nas ruas do município. O Quadro 1 contém as variáveis consideradas para a análise da autogestão de ativos biológicos a partir da estrutura de autogovernança:
Quadro 1: Variáveis utilizadas para análise da autogestão de ativos biológicos a partir da estrutura de autogovernança.

\begin{tabular}{|c|c|}
\hline VARIÁVEIS & $\begin{array}{l}\text { CONDICCÕES P/ } \\
\text { EFETIVIDADE }\end{array}$ \\
\hline $\begin{array}{l}\text { Definição de } \\
\text { limites do } \\
\text { sistema de } \\
\text { recursos }\end{array}$ & $\begin{array}{l}\text { Limites bem } \\
\text { definidos }\end{array}$ \\
\hline $\begin{array}{c}\text { Definição de } \\
\text { limites do grupo } \\
\text { de apropriadores }\end{array}$ & $\begin{array}{c}\text { Limites } \\
\text { claramente } \\
\text { identificados }\end{array}$ \\
\hline $\begin{array}{l}\text { Compartilhamento } \\
\text { das normas }\end{array}$ & $\begin{array}{c}\text { Normas } \\
\text { compartilhadas }\end{array}$ \\
\hline $\begin{array}{l}\text { Apropriação } \\
\text { das unidades } \\
\text { de recursos }\end{array}$ & Baixo nível \\
\hline $\begin{array}{c}\text { Dependência } \\
\text { dos membros } \\
\text { em relação ao } \\
\text { sistema de } \\
\text { recursos }\end{array}$ & Altos níveis \\
\hline $\begin{array}{l}\text { Equidade na } \\
\text { alocação dos } \\
\text { benefícios da } \\
\text { apropriação } \\
\text { dos recursos }\end{array}$ & Alocação justa \\
\hline $\begin{array}{c}\text { Procedência } \\
\text { das Instituições }\end{array}$ & $\begin{array}{c}\text { Regras definidas } \\
\text { pela tomada de } \\
\text { decisão coletiva, } \\
\text { atendendo as } \\
\text { especificidades } \\
\text { locais }\end{array}$ \\
\hline $\begin{array}{l}\text { Ajustes dos } \\
\text { limites da } \\
\text { colheita com a } \\
\text { regeneração } \\
\text { dos recursos }\end{array}$ & $\begin{array}{l}\text { Há } \\
\text { ajuste dos limites } \\
\text { da colheita } \\
\text { necessários para a } \\
\text { regeneração dos } \\
\text { recursos }\end{array}$ \\
\hline $\begin{array}{c}\text { Influência do } \\
\text { estado no poder } \\
\text { de autoridades } \\
\text { locais }\end{array}$ & $\begin{array}{c}\text { Governos centrais } \\
\text { não devem } \\
\text { enfraquecer a } \\
\text { entidades locais }\end{array}$ \\
\hline
\end{tabular}

Fonte: Adaptado de Agrawal apud Pinto (2014).

Os peixes inseridos no processo de piscicultura rudimentar foram considerados ativos biológicos a partir da mensuração, controle e benefícios econômicos, conforme preposto na Norma Brasileira de Contabilidade Técnica Geral (NBC TG) 29. Para consecução da 
pesquisa se utilizou de dados secundários dispostos em bancos oficiais e de dados primários, necessários para o estreitamento de foco empírico através das unidades empíricas de análise, coletados por meio de pesquisa de campo para aplicação de um roteiro de entrevistas semiestruturadas junto aos chefes de família, conforme o Quadro 2:

Quadro 2: Orientações para o Roteiro de pesquisa de Campo

\begin{tabular}{|l|}
\hline 1 - Caracterização do entrevistado \\
\hline $\begin{array}{l}\text { Lideres das associações de moradores } \\
\text { por ser seus representantes formais, } \\
\text { lideranças reconhecidas pelos grupos } \\
\text { étnicos, chefes de família e moradores. }\end{array}$ \\
\hline $\begin{array}{l}\text { 2 - Temas do Roteiro de entrevista } \\
\text { semiestruturado }\end{array}$ \\
\hline $\begin{array}{l}\text { Sistema de Recursos, Unidades de } \\
\text { Recurso, Estrutura de Governança, } \\
\text { Instituições e Autogestão. }\end{array}$ \\
\hline $\begin{array}{l}\text { 3 - Locais e Circunstâncias de Pesquisa } \\
\text { de Campo }\end{array}$ \\
\hline - Território coletivo quilombola. \\
- Sedes das Associações de moradores. \\
- Atividades cotidianas dos quilombolas \\
- Reunião da Associação de Moradores \\
\hline 4 - Período da Pesquisa de Campo \\
\hline $\begin{array}{l}\text { Janeiro de } 2016 \text { a dezembro de } 2017 \\
\text { - Aplicação de roteiro de entrevista } \\
\text { semiestruturados }\end{array}$ \\
\hline - Estratégias de Pesquisa de Camporvação direta \\
\hline - Conversas informais \\
\hline da associação de moradores
\end{tabular}

Fonte: Elaboração Própria.

\section{RESULTADOS E DISCUSSÕES}

A região do Acará "notabilizouse no século XIX pelo número de escravos, por quilombos formados e intrincados nas matas e ainda pelo estalido de uma revolta de cultivadores que a historiografia insere na gesta revolucionária da Cabanagem" (MARIN, 2000, p. 6). Em "1729,

a Coroa proibiu a utilização de mão-de-obra indígena nos canaviais, engenhos e áreas de cultivo do tabaco e os cultivadores foram pressionados para adquirir o escravo de origem africana" (MARIN, 2000, p. 9).

Dessa forma, os

$$
\begin{aligned}
& \text { produtores de açúcar e } \\
& \text { aguardente, do vale do } \\
& \text { Tocantins e do Acará, } \\
& \text { tiveram facilidades para } \\
& \text { adquirir escravos de } \\
& \text { origem africana com a } \\
& \text { montagem do mercado } \\
& \text { de escravos organizado } \\
& \text { pela Companhia do Grão- } \\
& \text { Pará e Maranhão (1755- } \\
& \text { 1777) responsável pela } \\
& \text { importação (MARIN, } \\
& \text { 2000, p. 9). }
\end{aligned}
$$

A história oral resgatada a partir das memórias dos quilombolas mais velhos remete ao início desta, na qual é resultado de um processo histórico de ocupação por negros que migraram do município de Acará. Esses negros eram descendentes diretos de escravos vindos da África, os primeiros que chegaram à região demarcaram seus territórios com estacas. Destaca-se que a distribuição de sesmarias concedidas desde 1707 até 1824 nos espaços banhados pelo rio Acará e seus afluentes se depreende certa concentração de escravos e, mais do que eles, a organização do trabalho em unidades familiares (MARIN, 2000)

Ainda conforme a história oral, houve um movimento de autoorganização e união dos ribeirinhos locais para luta de direitos dos negros e titulação do seu território. A mobilização e a auto-organização objetivaram clamar por políticas de reconhecimento étnico pelo Estado, numa tentativa de afirmar suas formas de apropriação do território, de transferência de herança, de culto e de reprodução social. Essa auto-organização em conjunto com a autogovernança enquanto estrutura de compartilhamento de poder, impulsionou a criação de instituições culturalmente legítimas e reconhecidas como comunidades quilombolas. Dessa forma, percebe-se que os limites da base comum de recursos são bem definidos e corresponde ao território institucionalizado da comunidade quilombola.

A comunidade cria arranjos de direitos de propriedade em regime de propriedade comum firmados como "acordo" no espaço formal para tomada de decisão coletiva via associação de moradores. Dessa forma, estes grupos sociais étnicos adaptados ao ambiente desenvolveram instituições próprias para garantir sua permanência e sustentabilidade no território, por meio de arranjos de direito de propriedade onde "a natureza individualista e concentradora da propriedade privada convive com o sistema de uso de recursos comuns de "populações tradicionais" (BARBOSA; MARIN, 2010, p. 32). Esse fato pode entendido como uma estratégia de organização do território, preconizando formas socialmente equitativas de vida e reprodução social. Isso porque, McKean e Ostrom (2011) discorrem sobre a possibilidade de um grupo de coproprietários compartilhar a propriedade do estoque produtivo de um sistema de recursos sem dividilo, mas dividindo o fluxo de unidades de uso em direitos de propriedade individual. 
Figura 1: Reunião com o representante da comunidade.

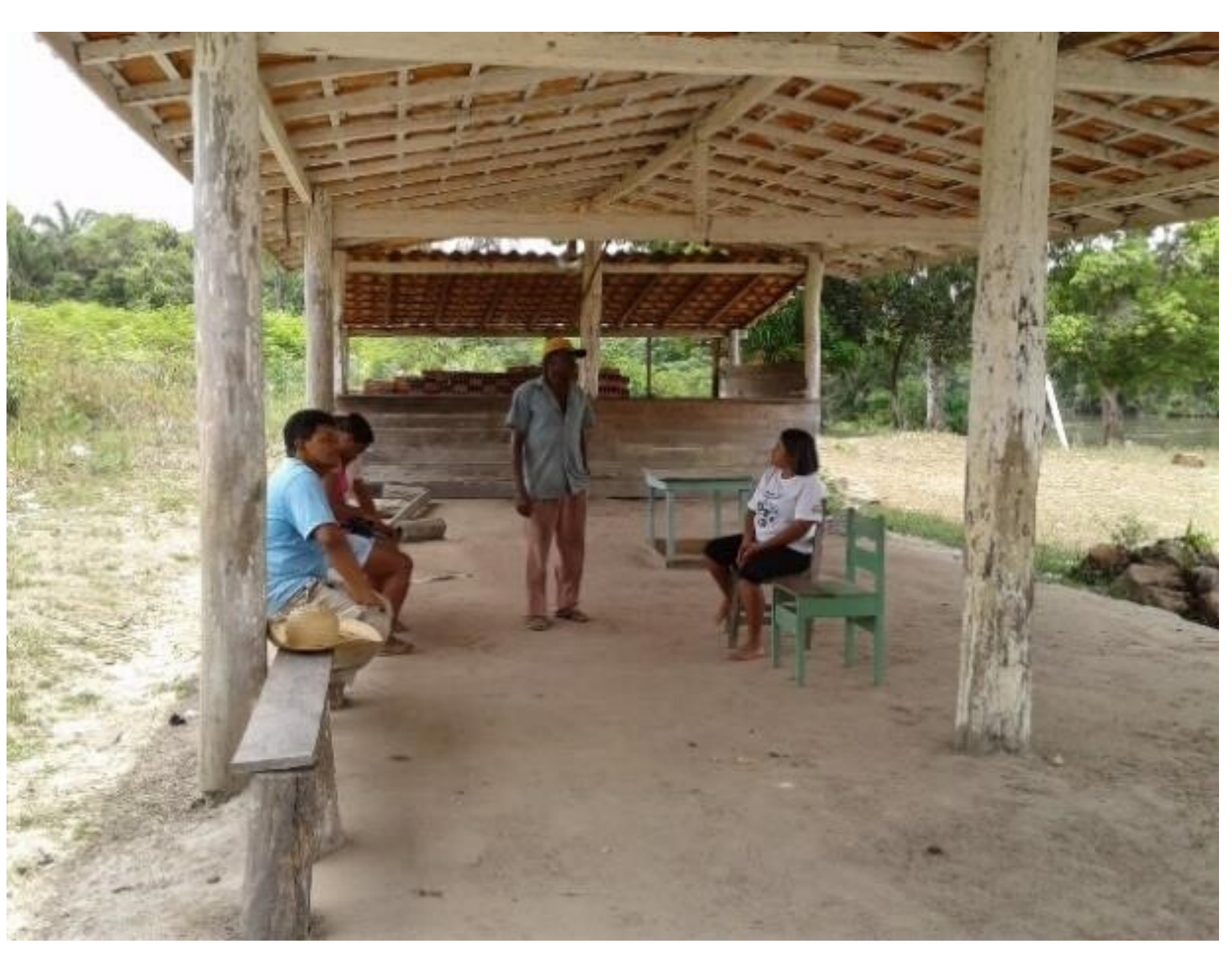

Fonte: Autoria própria.

A associação de moradores assume um papel mais amplo do que o preconizado na legislação, o qual é decidir sobre cargos eletivos. Esse espaço deliberativo assume o papel de espaço para a tomada de decisão coletiva, ou seja, a autogestão. Isso porque, nesse espaço também ocorre a definição de consenso mínimo, definição de instituições sobre o uso e apropriação de unidades de base comum de recursos, estratégias de apropriação, obrigações e responsabilidades dos coproprietários, monitoração, sancionamento e resolução de conflitos, evidenciando a existência da autogovernança.

A comunidade coletivamente deliberou e elaborou, por meio da autogestão e no âmbito da autogovernança, em assembleia na associação de moradores um arranjo de direito em regime de propriedade comum em que cada coproprietário pode explorar os recursos naturais que há em "sua propriedade". A propriedade individual é um território simbólico uma vez que legalmente $\mathrm{O}$ território da comunidade quilombola possui titulação coletiva em nome da associação de moradores.

É comum existir o minério argila, recurso natural não-renovável. Após a retirada da argila, e alienação no caso da argila com potencial comercial, são feitos tanques para prática de piscicultura rudimentar. Os peixes são destinados ao consumo interno, ou seja, subsistência, ou venda em pequena escala no mercado local. Destaca-se que nas propriedades onde não há argila comercial há a escavação do tanque para piscicultura rudimentar voltada para o consumo interno.

Figura 2: Tanque de piscicultura rudimentar na Comunidade Forte do Castelo

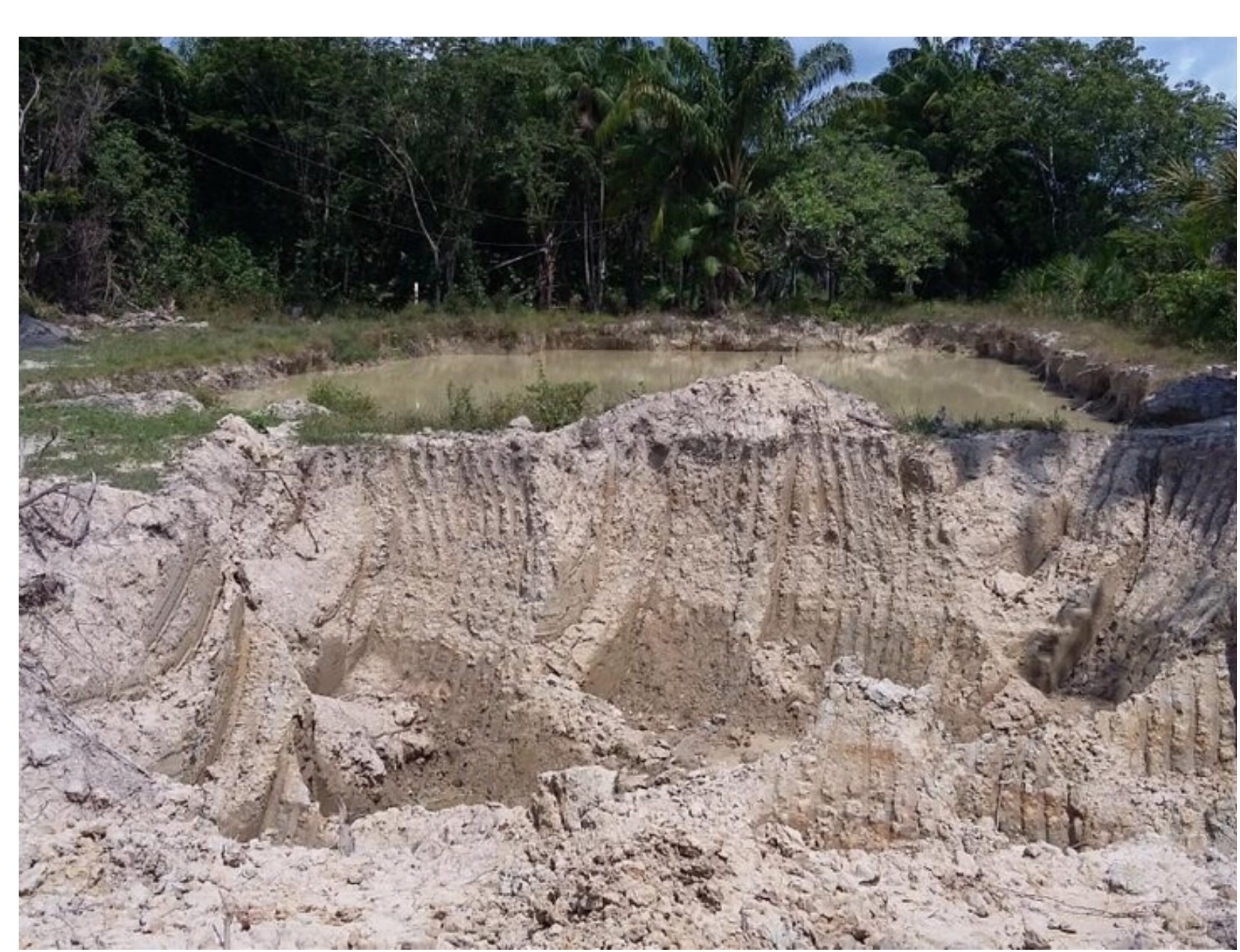

Fonte: Autoria própria.

Conforme as informações já expostas até aqui, ao se relacionar os conceitos e propriedades do ativo contabilmente (o bem só pode ser reconhecido se for de posse da pessoa e/ou entidade). Reitera-se que essa posse se afirma pelo processo histórico, e é garantido pela identidade étnica de quilombola. De outro modo, a mensuração base dos Ativos Biológicos é o valor justo de mercado obtido, na maioria das vezes, por meio de um atravessador ou por um quilombola que consegue escoar a sua própria produção. O valor justo é obtido baseado nos preços praticados no mercado local. Na especificidade amazônica, esse valor é o mesmo do escoamento da produção. Dessa forma, esse ativo atende os requisitos que as normas contábeis exigem.
Figura 3: Rio Acará-Mirim as margens da Comunidade Ramal do Castelo.

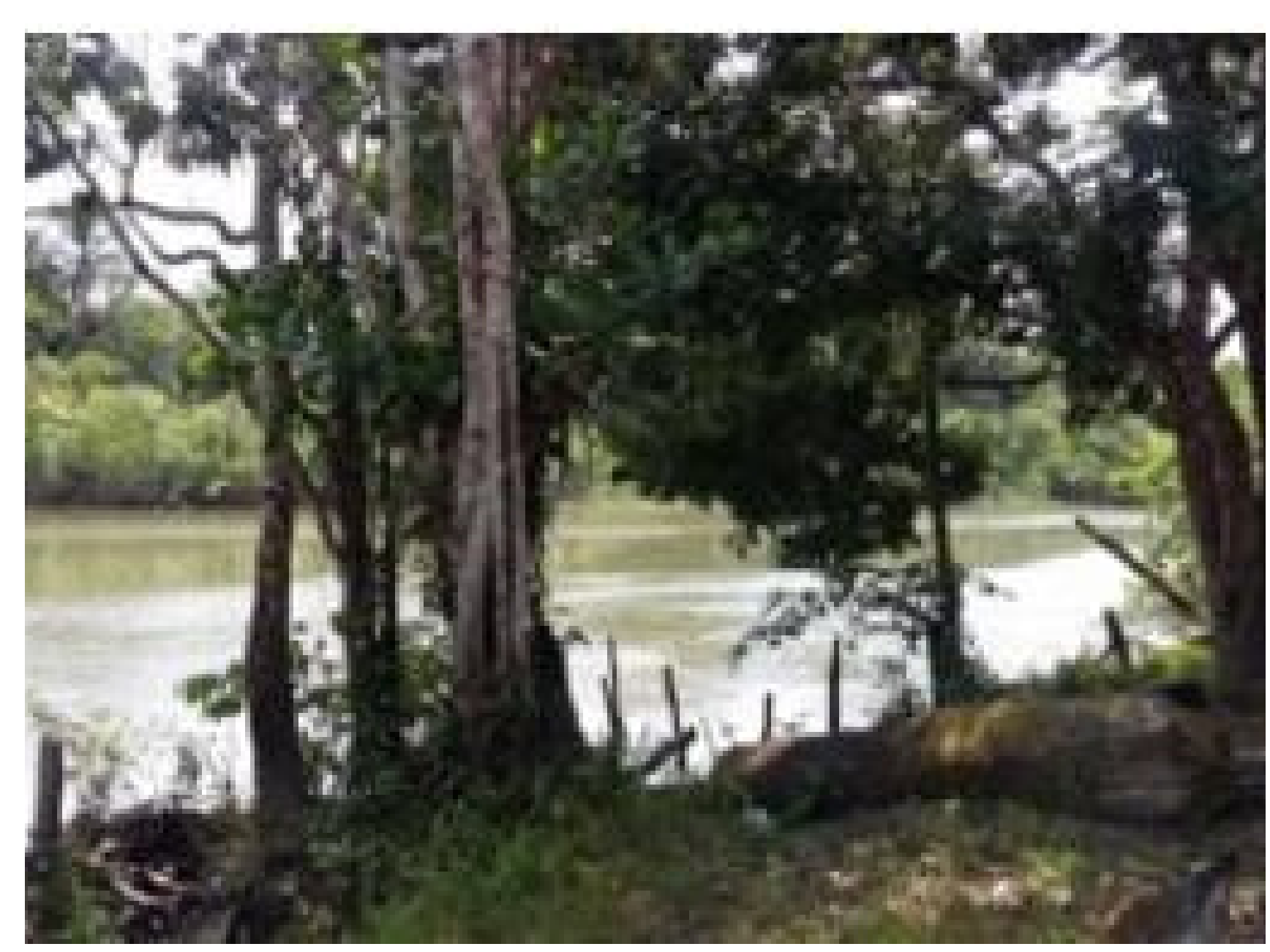

Fonte: Autoria própria.

O processo produtivo no qual o ativo biológico peixe está inserido causa impactos ambientais, porém existem impactos sociais significativos evidenciadas pela tomada de decisão coletiva, formas equitativas de organização social e técnicas de baixo impacto ambiental orientadas por traços culturais que são seletivamente reafirmados e reelaborados.

Figura 4: Ponte de acesso ao rio em uma residência comunidade.

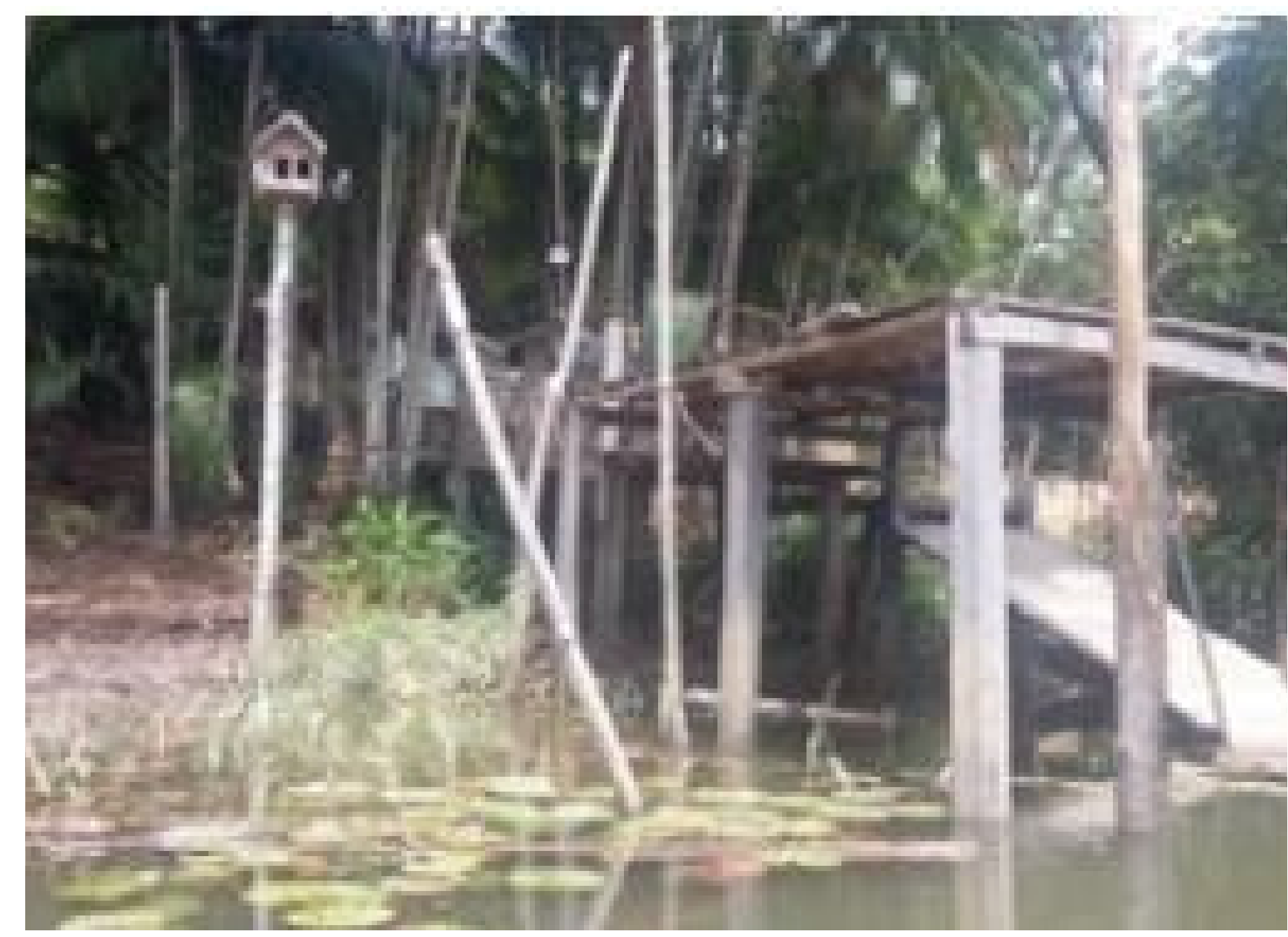

Fonte: Autoria própria

O peixe inserido do processo produtivo orientado para a subsistência ou venda em pequena escala é um ativo biológico. Isso porque, conforme a NBC TG 29 se trata de um animal vivo. Adicionalmente, o processo histórico geracional de ocupação do território e a identidade étnica de quilombola garante o controle sobre tal ativo. Os arranjos de direito de propriedade são estabelecidos por meio da autogestão enquanto prática de tomada de decisão coletiva a partir da autogovernança. 
Destaca-se que a existência da associação de moradores enquanto espaço de deliberação é fundamental nesse processo. Os peixes são mensurados tendo como base o valor justo, - qual na configuração do processo quilombola é um valor de mercado obtido em duas situações: a) na maioria das vezes estabelecido pelo atravessador e b) pelo mercado local que impõe ao quilombola ao escoar a sua própria produção. Dessa forma, o valor justo não reflete os custos para a produção.

\section{CONCLUSÃO}

Conforme a análise dos resultados e rebuscando o objetivo desse estudo é possível concluir que a autogovernança na comunidade influencia todas as atividades desenvolvidas, desde as individuais até as coletivas. A autogestão, tomada de decisão coletiva, é exercida por meio de assembleias que decidem diversas questões, desde a delimitação das propriedades que são subdividas em famílias, até as formas de exploração dos recursos comuns. Algumas atividades como a extração de argila, evidenciam impactos ambientais, pois utilizam os recursos naturais modificando a estrutura natural. $\bigcirc$ objetivo das pisciculturas rudimentares consiste em contribuir para incremento da renda dos grupos familiares da comunidade quilombola, reprodução social e sobrevivência.

Os resultados demonstram ainda que há uma estrutura de compartilhamento de poder, ou seja, a autogovernança na comunidade quilombola Forte do Castelo (PA). Identificou-se a autogestão, a qual é a prática de tomada de decisão coletiva. Embora o processo de piscicultura no qual o peixe, ativo biológico, está inserido traga impactos ambientais, identificou-se que o objetivo da piscicultura rudimentar consiste em contribuir para incremento da renda dos grupos familiares da comunidade quilombola, reprodução social e sobrevivência. Por fim, existem impactos sociais significativos evidenciados pela tomada de decisão coletiva, formas equitativas de organização social e técnicas de baixo impacto ambiental orientadas por traços culturais que são, seletivamente, reafirmados e reelaborados.

Na perspectiva dos ativos biológicos comercializados pela comunidade, que no caso são provenientes da atividade de piscicultura, eles seguem as regras de avaliação conforme a norma NBC TG 29 (R2), sendo que $O$ seu valor de comercialização é mensurado pelo mercado (valor justo), que no caso da comunidade são os atravessadores que compram no intuito de revenda.

Essa pesquisa se limita por ser uma análise exploratória em uma única comunidade quilombola. Sugere-se a ampliação do escopo para outras unidades empíricas de análise na complexidade amazônica. Tais populações são detentoras de traços sociais e culturais complexos, sistemas de organização sociopolíticos próprios distintos, instituições legítimas, formas de auto-organização distintas, além de arranjos de direito de propriedade complexos.
Portanto, este trabalho possui como unidade empírica de análise a comunidade quilombola Forte do Castelo na região do Marupaúba, localizada no município de Tomé-Açu (PA). Focou-se na estrutura de autogovernança e na autogestão de ativos biológicos, em particular o peixe, inserido no processo produtivo da piscicultura rudimentar.

\section{REFERÊNCIAS}

AllegretTI, Mary. A construção social de políticas públicas. Chico Mendes e o movimento dos seringueiros. Desenvolvimento e Meio Ambiente, 18, p.39-59, 2008

ARRUDA, Rinaldo. "Populações Tradicionais" e a Proteção dos Recursos Naturais em Unidades de Conservação. Ambiente \& Sociedade, 2(5), 1999

BARBOSA, Maria Betanha Cardoso; MARIN, Rosa Elizabeth Acevedo. Manejo e uso comum dos recursos naturais em populações quilombolas no Vale do Rio Capim. Novos Cadernos NAEA. 13(1), p.27-45, 2010.

BARROS, Henrique da Gama. Os grandes sistemas de organização da economia agrícola. Lisboa: Livraria Sá da Costa Editora, 1975

BRASIL. Decreto no 6.040 - Política Nacional de Desenvolvimento Sustentável dos Povos e Comunidades Tradicionais. 7 de fevereiro de 2007 Disponível em: https://bityli.com/GfTjK. Acesso em: 14 set. 2017.

CANÇADO, Ailton Cardoso. Fundamentos teóricos Da Gestão Social. 2008. Tese (Doutorado em Administração). Programa de PósGraduação em Administração, Universidade Federal de Lavras, Lavras, 2011.

CANCCADO, Airton Cardoso et al. Gestão social: reflexões teóricas e conceituais. Cadernos EBAPE, 9(3), p.681-703, 2014. 
CARDOSO, Luis Fernando Cardoso e. "O suor marca a terra": trabalho, direito e território quilombola na llha do Marajó, Pará. Ambiente \& Sociedade, XVIII(2), p.77-96, 2015.

CFC - CONSELHO FEDERAL DE CONTABILIDADE. Norma Brasileira de Contabilidade Técnica Geral NBC TG 46 (R2) - mensuração do valor justo. Brasília, DF, 2017. Disponível em: https://bityli.com/OPEMO. Acesso em: O1 jul. 2018.

Norma Brasileira de Contabilidade Técnica Geral NBC TG 29 (R2) - ativo biológico e produto agrícola. Brasília, DF, 2015. Disponível em: https://bityli.com/oVoFx. Acesso em: 28 fev. 2018

CPC 29. Comitê de Pronunciamentos Contábeis. 2009. Disponível em: https://bityli.com/gSWt3. Acesso em: 16 set. 2009

CUNHA, Manoela Carneiro da; ALMEIDA, Mauro. Populações tradicionais e conservação ambiental. In: CAPOBIANCO, João Paulo Ribeiro et al. (Orgs.) Biodiversidade na Amazônia brasileira: avaliação e ações prioritárias para a conservação, uso sustentável e repartição de benefícios. São Paulo: Instituto Socioambiental, 2001.

DIEGUES, Antonio Carlos et al. Biodiversidade e Comunidades Tradicionais no Brasil. São Paulo: NUPAUB-USP, PROBIO-MMA, CNPq, 2000.

DIEGUES, Antônio Carlos. Repensando e Recriando as Formas de Apropriação Comum dos Espaços e Recursos Naturais. In: DIEGUES, Antônio Carlos; MOREIRA, André de Castro C. (Orgs.). Espaços e recursos naturais de uso comum. São Paulo: Napaub-USP, 2011

FUNDAÇÃO PALMARES. 2007. Disponível em: https://bityli.com/hCCJj. Acessado em: 22/11/2007

GIUCCI, Guillermo. Viajantes do Maravilhoso: O Novo Mundo. São Paulo: Companhia das Letras, 1992.

HENDRIKSEN, Eldon, VAN BREDA, Michael. Teoria da Contabilidade. São Paulo: Atlas, 1999.
HOMMA, Alfredo Kingo Oyama. A dinâmica do extrativismo vegetal na Amazônia: uma interpretação teórica. Belém: Embrapa-CPATU, 1990.

IASC - International Accounting Standards Committee. Framework for the Preparation and Presentation of Financial Statements. Londres: IASC, 1989

IFRS - International Financial Reporting Standards. IAS 41 Agriculture. [S. I.]: IFRS, 1999. Disponível em: https://bityli.com/Uaceo. Acesso em: 9 out. 2018

LEITE, Ilka Boaventura. Os Quilombos No Brasil: Questões Conceituais E Normativas. Etnográfica, IV, p.333354, 2000

MARIN, Rosa Elizabeth Acevedo. Camponeses, donos de engenhos e escravos na região do Acará nos séculos XVIII e XIX. Paper do NAEAUFPA, 153, p.1-26, 2000

MARION, Jose Carlos. Contabilidade Básica. São Paulo: Atlas, 2009.

MARION, Jose Carlos; IUDíCIBUS, Sergio de. Curso de contabilidade para não contadores. São Paulo: Atlas, 2011

MELO, Sonia Aparecida Beato Ximenes de; MELO, André Ximenes de; SILVA, Fabricio Schwanz da. Perfil dos Extrativistas de Baru no Pantanal. Desafio Online, 3(3), p.1219-1234, 2015.

MCKEAN, Margaret A.; OSTROM Elianor. Regimes de propriedade comum em florestas: somente uma relíquia do passado? In: DIEGUES, Antônio Carlos; MOREIRA, André de Castro C (Orgs.). Espaços e recursos naturais de uso comum. São Paulo: Napaub-USP, 2011

OSTROM, Elianor. Governing the Commons: The Evolution of Institutions for Collective Action. Reino Unido: Cambridge University Press, 1990.

OSTROM, Elianor et al. Revisiting the Commons: Local Lessons, Global Challenges. Science, 284, p.278-282, 1999.
PRICE, Richard. Palmares Poderia Ter Sido. In.: REIS, João José; GOMES, Flávio dos Santos. Liberdade por um fio. São Paulo: Cia das Letras, 1996, p. 52-59.

RAGIN, Charles; BECKER, Howard Saul. What Is a Case?: Exploring the Foundations of Social Inquiry. Illinois: Cambridge University Press, 1992.

RECH, llirio José; PEREIRA, Clesia Camilo; PEREIRA, Ivone Vieira; CUNHA, Moisés Ferreira. IAS 41 Agriculture: Um Estudo da Aplicação da Norma Internacional de Contabilidade às Empresas de Pecuária de Corte. Contabilidade, Gestão e Governança, 20(2), 2016

WANDELEY, Carlos Alexandre Nascimento; SILVA, Anderson Chaves: LEAL, Rodrigo Barreiros. Tratamento Contábil de Ativos Biológicos e Produtos Agrícolas: uma Análise das Principais Empresas do Agronegócio Brasileiro. Pensar Contábil, 14(53), p.52-62, 2012. 


\section{Artigo recebido em: 28 Set 2019 I Artigo aprovado em: 18 Maio 2020.}

[i] Graduado em Ciências Contábeis pela Universidade Federal Rural da Amazônia (UFRA). Especialista em Auditoria, Compliance e Gestão de Risco (UNISA) e Gestão Hospitalar (FAVENI). Tutor nos cursos de Administração, Serviço Social e Contabilidade da UNISA e professor do curso de Ciências Contábeis da Faculdade Pitágoras, em Paragominas (PA)

Orcid: https://orcid.org/0000-0003-0946-9078

E-mail: josuecarvalho911@gmail.com

[ii] Professora da Universidade Federal Rural da Amazônia (UFRA). Doutora em Administração pela Universidade da Amazônia (PPAD/UNAMA) Líder do Grupo de Pesquisa Multidisciplinar Amazônia (GEMAM/UFRA) e pesquisadora do Núcleo de Estudos em Contabilidade e Meio Ambiente (NECMA/USP).

Orcid: https://orcid.org/0000-0001-8707-9492.

E-mail: yniscristine@gmail.com

[iii] Professora da Universidade Federal Rural da Amazônia (UFRA). Doutora em Administração pela Universidade da Amazônia (PPAD/UNAMA).

Orcid: https://orcid.org/0000-0001-9238-4651.

E-mail: ticiane.ufra@gmail.com 